\title{
EFEITO DO LOCAL DE COLETA NAS CARACTERÍSTICAS DE SEMENTES DE CAPIM-GORDURA (Melinis minutiflora P. Beauv.) NO DISTRITO FEDERAL, BRASIL ${ }^{1}$
}

\author{
RICARDO CARMONA², CARLOS ROMERO MARTINS ${ }^{3}$
}

\begin{abstract}
RESUMO - O presente trabalho teve como objetivo avaliar o efeito do local de coleta no índice de esterilidade, na viabilidade e na dormência de sementes de capim-gordura, uma importante gramínea invasora de áreas de proteção ambiental nos cerrados brasileiros. Sementes das cultivares Roxo e Cabelo-de-Negro foram coletadas nas seguintes unidades de conservação do Distrito Federal, Brasil: Parque Nacional de Brasília, Reserva Ecológica do IBGE e Estação Ecológica de Águas Emendadas. Avaliaram-se o percentual de sementes cheias (contendo cariopse), a viabilidade e a dormência dessas sementes. A viabilidade das sementes dessa espécie pode ser adequadamente avaliada mediante o teste de germinação em temperaturas alternadas de $20-30^{\circ} \mathrm{C}$, com substrato umedecido em solução de nitrato de potássio a $0,5 \%$ com luz e a dormência a $25^{\circ} \mathrm{C}$, em água e no escuro. Observou-se grande variação na porcentagem de sementes cheias em função do local de coleta, especialmente na cultivar Roxo (17,5\% a 36,1\%). O local de coleta também afeta a dormência das sementes de ambas cultivares $(20 \%$ a $80 \%)$ e a viabilidade das sementes apenas da cultivar Roxo ( $80 \%$ a 96\%). Esses resultados ajudam a explicar o comportamento ecológico de Melinis minutiflora.
\end{abstract}

Termos para indexação: germinação, dormência, esterilidade de espiguetas, invasoras.

\section{EFFECT OF THE COLLECTING PLACE ON SEED CHARACTERISTICS OF Melinis minutiflora P. Beauv. ON DISTRITO FEDERAL, BRAZIL}

\begin{abstract}
The objective of the present study was to evaluate the effect of the collecting location on the sterility, viability and dormancy of Melinis minutiflora seeds, an important weed of conservation units in the cerrado regions in Brazil. Seeds of two cultivars, Roxo and Cabelo-deNegro, were collected in the following conservation units, located in the Federal District (Distrito Federal), Brazil: Parque Nacional de Brasília, Reserva Ecológica do IBGE and Estação Ecológica de Águas Emendadas. The percentage of full seeds (containing caryopsis), seed viability and seed dormancy were evaluated. The results showed that seed viability was adequately evaluated using a germination test at the alternating temperatures of $20-30^{\circ} \mathrm{C}$, in potassium nitrate at $0.5 \%$ with light, and seed dormancy at $25^{\circ} \mathrm{C}$, in water and darkness. The collecting location affected the percentage
\end{abstract}

${ }^{1}$ Submetido em 07/05/2007. Aceito para publicação em 13/01/2008.

${ }^{2}$ Ag. Ph.D. Professor Adjunto, Faculdade de Agronomia e Medicina Veterinária, Universidade de Brasília. 70.910-970 Brasília-DF. e-mail:rcarmona@unb.br.

${ }^{3}$ Eng. Florestal Dr. em Ecologia, Ibama/Sede/Diretoria de Licenciamento, 70.8118-900 Brasília-DF. carlos.martins@ibama.gov.br. 
of full seeds, specially in the cultivar Roxo (17.5\% to $36.1 \%)$. It also affected seed dormancy in both cultivars $(20 \%$ to $80 \%)$ and seed viability in the cultivar Roxo $(80 \%$ to $96 \%)$. These results help to explain the ecological behavior of Melinis minutiflora.

Index terms: germination, dormancy, sterility of spikelets, weeds.

\section{INTRODUÇÃO}

O capim-gordura provavelmente foi introduzido no território brasileiro no século XIX, de forma acidental, por ocasião do tráfico intenso de escravos, que ocorreu no período colonial (Parsons, 1972; Filgueiras, 1990). O centro de origem dessa espécie é o continente africano e o território brasileiro é caracterizado como centro de desenvolvimento ou dispersão da mesma (Vello, 1975). Segundo Bogdan (1977), o gênero Melinis contém de 20 a 25 espécies. No Brasil, ocorrem apenas as espécies Melinis minutiflora e Melinis repens e, entre as cultivares de Melinis minutiflora, as mais conhecidas são Roxo, Cabelo-de-Negro, Branco e Francano (Brasil, 1953), sendo encontradas no Distrito Federal apenas as duas primeiras.

Durante aproximadamente 120 anos, o capim-gordura e o capim jaraguá (Hyparrhenia rufa) foram as principais forrageiras utilizadas para a formação de pastagens no Brasil Central. Na década de 60 do século passado, dos 123 milhões de hectares de pastagens existentes no Brasil, cerca de 30 milhões eram cultivados com capim-gordura. Nos anos setenta do século passado, os pecuaristas iniciaram um processo de substituição do capim-gordura por espécies mais produtivas do gênero Urochloa (Brachiaria), tais como $U$. decumbens, $U$. brizantha, U. ruzizienses e $U$. humidicola (Curado e Costa, 1980; Aronovich e Rocha, 1985).

Devido à sua boa adaptabilidade às condições edafoclimáticas do Brasil Central, apesar de deixar de ser cultivado, o capim-gordura persistiu nessa região especialmente emáreas de unidades de conservação, mudando seu status de espécie cultivada para indesejada, devido à sua forte capacidade de interferência com espécies nativas, principalmente com outras gramíneas nativas (Filgueiras, 1990). Atualmente, a presença dessa espécie é bastante comum no Cerrado especialmente nas áreas de unidades de conservação (Pivello et al., 1992). No Distrito Federal, ocorre no Parque Nacional de Brasília, na Reserva Biológica da Contagem, na Estação Ecológica de Águas Emendadas, no Jardim Botânico, na Reserva Ecológica do IBGE e na Floresta Nacional de Brasília, entre outras localidades. A extensão das áreas colonizadas por essa gramínea nas áreas protegidas do Distrito Federal, à exceção do Parque Nacional de Brasília, não foi ainda devidamente levantada (Martins, 2006).

Uma das principais características do capim-gordura que condicionam seu rápido desenvolvimento e expansão refere-se à sua capacidade reprodutiva. Suas sementes são produzidas em grandes quantidades e são facilmente disseminadas pelo vento (Freitas e Pivello, 2005; Filgueiras, 1990). O conhecimento das características reprodutivas dessa espécie pode constituir importante ferramenta para a proposição de métodos racionais de manejo, reduzindo assim os problemas por ela causados em unidades de conservação.

O presente trabalho tem como objetivo avaliar o efeito do local de produção nas seguintes características das sementes de capim-gordura: viabilidade, dormência e percentagem de espiguetas cheias (contendo cariopse).

\section{MATERIAL E MÉTODOS}

\section{Coletas de sementes}

Unidades de dispersão de capim-gordura (espiguetas cheias e vazias) das cultivares Roxo e Cabelo-de-Negro, doravante referidas como sementes (Allred, 1982), foram coletadas nas seguintes localidades do Distrito Federal, Brasil: Parque Nacional de Brasília (PARNA Brasília coordenadas $15^{\circ} 44^{\prime} \mathrm{S}$ e $47^{\circ} 57^{\prime} \mathrm{W}$ ), Reserva Ecológica do IBGE (RECOR IBGE - coordenadas $15^{\circ} 56^{\prime}$ 'S e $47^{\circ} 53^{\prime}$ W) e Estação Ecológica de Águas Emendadas (ESEC AE - coordenadas $15^{\circ} 32^{\prime} \mathrm{S}$ e $47^{\circ} 33^{\prime} \mathrm{W}$ ). O clima na região é caracterizado como tropical de altitude, com verões úmidos e chuvosos e invernos secos e relativamente frios. A temperatura média anual é de cerca de $21^{\circ} \mathrm{C}$, a média das máximas de $29^{\circ} \mathrm{C}$ em setembro, e a média das mínimas de $12^{\circ} \mathrm{C}$ nas madrugadas do mês de julho. A umidade relativa do ar é de aproximadamente $70 \%$, podendo chegar aos $20 \%$ ou menos durante o inverno (Brasil, 2009). 
Para fins de coleta, foram cortadas manualmente e aleatoriamente 10 inflorescências de cada cultivar, no mês de junho de 2004, mediante o método de caminhamento através de transectos imaginários. $\mathrm{O}$ material cortado foi seco a sombra, pelo período de dois meses, no Laboratório de sementes da Faculdade de Agronomia e Medicina Veterinária da Universidade de Brasília. O material foi trilhado e limpo manualmente e as sementes acondicionadas em sacos de papel permeável.

\section{Parâmetros estudados}

A porcentagem em número de sementes cheias (contendo cariopse) foi determinada mediante separação e pesagem das frações espiguetas cheias e vazias. As espiguetas cheias foram separadas das vazias mediante uso de assoprador (marca General Seed Blower) por três minutos, previamente regulado para eliminar apenas as espiguetas vazias. Devido a presença de aristas nas sementes da cv. Roxo, em cada operação no assoprador o peso máximo de cada porção de sementes não excedeu a $0,10 \mathrm{~g}$ para evitar o entrelaçamento entre as sementes.

Os testes de germinação, conduzidos apenas com sementes cheias, foram realizados em câmaras de germinação tanto nas temperaturas alternadas de $20^{\circ}$ $30^{\circ} \mathrm{C}$ (16/8horas) com luz florescente branca durante a temperatura mais elevada em nitrato de potássio a $0,5 \%$, como na temperatura de $25^{\circ} \mathrm{C}$ no escuro em água. Os testes de germinação foram realizados sobre papel, em placas de petri de poliestireno transparente forradas com duas folhas de papel filtro umedecidas com nitrato de potássio ou água, conforme o teste.

As avaliações de germinação foram realizadas diariamente nos testes em presença de luz, a fim de monitorar a evolução do processo germinativo, reumedecendo o substrato com água destilada sempre que necessário. Os testes na ausência de luz foram conduzidos envolvendose cada placa de petri com duas folhas de papel alumínio. Nesse caso, as placas foram seladas com fita adesiva para evitar o ressecamento do substrato.

Todos os tratamentos constaram de quatro repetições de 100 sementes cheias em delineamento inteiramente casualizado (Brasil, 1992). Os testes no escuro foram avaliados uma única vez, ao final das avaliações em presença de luz. Considerou-se germinada a semente que emitiu pelo menos $2 \mathrm{~mm}$ de radícula e/ou coleóptilo. Para fins de análise estatística, os dados obtidos nos testes de germinação, em porcentagem, foram previamente transformados em arco seno $\sqrt{\%} / 100$, para a normalização da sua distribuição.
Quando houve significância estatística no Teste de F, as médias foram comparadas pelo Teste de Tukey, ao nível de $5 \%$ de probabilidade.

\section{RESULTADOS E DISCUSSÃO}

Observou-se grande variação na percentagem de sementes cheias de capim-gordura, especialmente na cultivar Roxo (Tabela 1), cuja porcentagem de sementes cheias variou de 17,5 a $36,1 \%$ nos diferentes locais estudados. Os valores observados no referente ao percentual de sementes cheias estão de acordo com os observados em outros trabalhos com o capim-gordura, em que esse percentual variou de 25 a 40\% (Brasil, 1953; Rocha et al. 1965; Freitas e Pivello, 2005). Pelos resultados, é possível inferir que o capim-gordura apresenta alta taxa de esterilidade natural de sementes.

TABELA 1. Porcentagem de sementes cheias ( \pm desvio padrão) das cultivares Roxo e Cabelode-Negro de Melinis minutiflora (capimgordura), coletadas no ano de 2004, na Reserva Ecológica do IBGE (IBGE), no Parque Nacional de Brasília (PARNA) e na Estação Ecológica de Águas Emendadas (ÁGUAS).

\begin{tabular}{ccc}
\hline & \multicolumn{2}{c}{ Sementes cheias (\%) } \\
\cline { 2 - 3 } Local de coleta & Roxo & Cabelo-de-Negro \\
\hline IBGE & $36,1 \pm 7,8$ & $28,1 \pm 5,8$ \\
PARNA & $24,8 \pm 5,9$ & $27,7 \pm 6,1$ \\
ÁGUAS & $17,5 \pm 3,1$ & $24,6 \pm 6,2$ \\
\hline
\end{tabular}

As maiores percentagens de sementes cheias de ambas cultivares foram observadas nas sementes provenientes da Reserva Ecológica do IBGE, em seguida nas do Parque Nacional de Brasília e, por último, nas da Estação Ecológica das Águas Emendadas. O efeito de local de coleta na percentagem de sementes cheias provavelmente indica uma influência edafo-climática nesse parâmetro. Futuros estudos devem ser conduzidos para identificar que fatores ambientais influenciam de forma mais acentuada a esterilidade de espiguetas. No Brasil, o padrão mínimo de pureza para a produção de sementes de Melinis minutiflora $e ́$ de 30\% (BRASIL, 2008). 
Estudos com gramíneas nativas ainda são raros no Brasil, contudo Carmona et al. (1999), avaliando as características de sementes de 22 espécies de gramíneas nativas colonizadoras de áreas degradadas no cerrado, observaram que esse parâmetro é bastante variável entre gêneros. Esses autores propuseram uma classificação de acordo com o índice de espiguetas cheias, categorizando como de elevado índice de espiguetas cheias (superior a $50 \%$ ) espécies dos gêneros Aristida, Ctenium, Diectomis e Schizachyrium; como intermediário (25\% a 49\%) espécies dos gêneros Andropogon e Hypogynium; como baixo (5\% a 24\%) espécies de Paspalum, Setaria e Thrazia e muito baixo (inferior a 5\%) no gênero Axonopus. De acordo com essa classificação, o capim-gordura poderia ser categorizado como espécie apresentando de baixo a intermediário índice de espiguetas cheias.

As condições do teste em temperaturas alternadas, por serem altamente estimulantes de germinação para espécies gramíneas (Carmona et al., 1999), foram testadas para estimar a viabilidade das sementes. Já as condições de temperatura constante foram usadas para estimar a dormência das sementes (Carmona et al., 1999).As sementes cheias de ambas as cultivares, armazenadas durante 4 meses após colheita, apresentaram germinação baixa em temperatura constante $\left(25^{\circ} \mathrm{C}\right)$, em água e no escuro (Tabela 2). A exposição das sementes a temperaturas alternadas $\left(20^{\circ}-30^{\circ} \mathrm{C}\right)$, nitrato de potássio e luz resultou em germinação de $97 \%$ para a cultivar Roxo e de 94\% para Cabelo-de-Negro (Tabela 2). Esses resultados confirmam que as temperaturas alternadas usadas juntamente com luz e nitrato de potássio constituem condições bastante estimulantes para a germinação dessa espécie, podendo, dessa forma, serem usadas em testes de germinação de sementes de capim-gordura. Testes de germinação conduzidos nessas mesmas condições foram bastante estimulantes para sementes de espécies de gramíneas nativas do cerrado, coletadas no Distrito Federal (Carmona et al., 1998).

$\mathrm{Na}$ cultivar Cabelo-de-Negro, o efeito do local de coleta não foi aparente na germinação de sementes sob condições favoráveis, entretanto em temperatura constante e no escuro, esse efeito foi bastante evidente na germinação das sementes, variando de $12 \%$ no Parque Nacional de Brasília a $77 \%$ na Reserva Ecológica de Águas Emendadas (Tabelas 2 e 3). $\mathrm{Na}$ cultivar Roxo, o local de coleta afetou a germinação de sementes nas duas condições de temperaturas. A germinação das sementes da cultivar Cabelo-de-Negro foi, de forma geral, superior à das sementes da cultivar Roxo nas duas condições usadas para os testes de germinação (tabelas 2 e 3 ).
TABELA2. Germinação(\%) de sementes cheias de Melinis minutiflora, cultivares Roxo e Cabelo-deNegro, em temperaturas alternadas com luz e nitrato de potássio e constante no escuro e em água. Sementes coletadas no ano de 2004, na Estação Biológica do IBGE (IBGE), no Parque Nacional de Brasília (PARNA) e na Reserva Ecológica de Águas Emendadas (ÁGUAS).
Temperatura
Temperatura
alternada
constante

\begin{tabular}{ccccc}
\cline { 2 - 5 } $\begin{array}{c}\text { Local de } \\
\text { coleta }\end{array}$ & Roxo & $\begin{array}{c}\text { Cabelo- } \\
\text { de-Negro }\end{array}$ & Roxo & $\begin{array}{c}\text { Cabelo- } \\
\text { de-Negro }\end{array}$ \\
\hline IBGE & $93 \mathrm{a}$ & $93 \mathrm{a}$ & $13 \mathrm{~b}$ & $28 \mathrm{~b}$ \\
PARNA & $86 \mathrm{~b}$ & $96 \mathrm{a}$ & $11 \mathrm{~b}$ & $12 \mathrm{c}$ \\
ÁGUAS & $80 \mathrm{~b}$ & $93 \mathrm{a}$ & $22 \mathrm{a}$ & $77 \mathrm{a}$ \\
\hline
\end{tabular}

Médias seguidas da mesma letra, nas colunas, não diferem pelo Teste de Duncan a $5 \%$ de probabilidade.

A diferença de germinação entre os testes em temperaturas alternadas e constante deve-se, provavelmente, à dormência das sementes. Aparentemente, sementes pouco dormentes germinaram em ambas as condições, ao passo que sementes com dormência mais acentuada somente germinaram nas condições mais promotoras (temperaturas alternadas). Dessa forma, consideraram-se dormentes as sementes que germinaram na condição mais promotora, porém deixaram de germinar nas condições menos promotoras (Figura 1).

TABELA 3. Resumo das análises estatísticas acerca do efeito de cultivar, temperatura e local de coleta na germinação de sementes de capim gordura.

\begin{tabular}{crc}
\hline Causas de variação & \multicolumn{1}{c}{$\mathrm{F}$} & $\mathrm{Pr}>\mathrm{F}$ \\
\hline Cultivar $(\mathrm{C})$ & 79,24 & $<0,0001$ \\
\hline Temperatura $(\mathrm{T})$ & 1139,90 & $<0,0001$ \\
\hline $\mathrm{C} * \mathrm{~T}$ & 9,57 & 0,0038 \\
Local $(\mathrm{L})$ & 22,96 & $<0,0001$ \\
$\mathrm{C} * \mathrm{~L}$ & 18,56 & $<0,0001$ \\
$\mathrm{~T} * \mathrm{~L}$ & 52,40 & $<0,0001$ \\
$\mathrm{C} * \mathrm{~T} * \mathrm{~L}$ & 14,60 & $<0,0001$ \\
\hline
\end{tabular}




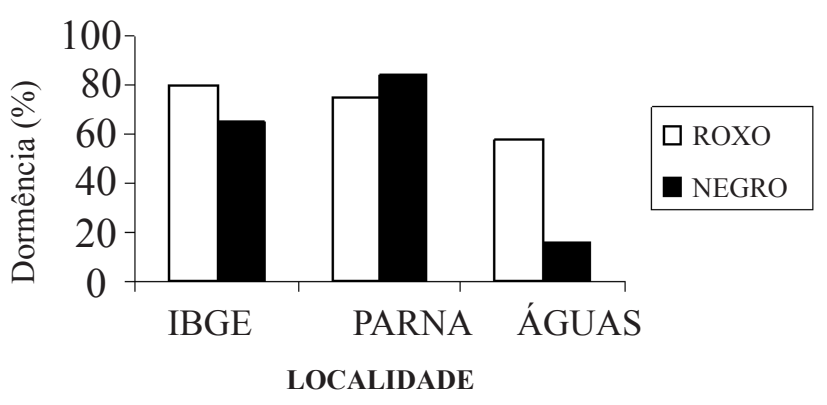

FIGURA. 1. Dormência (\%) de sementes cheias de Melinis minutiflora (cultivares Roxo e Cabelo-de-Negro) avaliada mediante a diferença de germinação entre os testes a 20$30^{\circ} \mathrm{C}$, luz e nitrato de potássio e $25^{\circ} \mathrm{C}$, água e escuro. Sementes coletadas no ano de 2004, na Estação Biológica do IBGE (IBGE), no Parque Nacional de Brasília (PARNA) e na Reserva Ecológica de Águas Emendadas (ÁGUAS).

Estudos conduzidos por Freitas e Pivello (2005) mostram que as sementes de capim-gordura apresentam ligeira dormência até um mês depois da colheita. Por sua vez, nas condições avaliadas, as sementes recém-colhidas de capimgordura apresentaram 4 meses, de forma geral, um elevado nível de dormência primária (ou inata), à exceção das sementes da cultivar Cabelo-de-Negro coletadas na Reserva Ecológica de Águas Emendadas. Esses dados reforçam a hipótese de que há efeito das condições ambientais no desenvolvimento de dormência em sementes de capim gordura. A dormência é um dos fatores que podem explicar o sucesso do capim gordura em colonizar áreas de proteção ambiental na região central do Brasil. Aliado a isso, o capim-gordura se caracteriza por produzir grande quantidade de sementes com elevado poder germinativo e rápido crescimento vegetativo.

Segundo Skerman e Riveros (1992), em condições de pastagens cultivadas, o capim-gordura pode alcançar uma produção de sementes de até $200 \mathrm{~kg} / \mathrm{ha}$. Por outro lado, Martins et al. (2004 b) relatam que em uma área de cerrado nativo colonizada espontaneamente em cerca de $50 \%$ por essa gramínea, a produção de sementes foi de 125 e $79 \mathrm{~kg} / \mathrm{ha}$ para as cultivares Roxo e Cabelo-de-Negro, respectivamente. Essas estratégias evolutivas possibilitam a essa espécie a formação de grandes bancos de sementes no solo (Freitas e Pivello, 2005; Martins, 2006). No Cerrado brasileiro, o capim gordura é considerado uma invasora bastante agressiva e que, uma vez estabelecido tanto em ambientes naturais quanto antropizados, tende a se consolidar e a se expandir nas áreas invadidas (Filgueiras, 1990; Freitas, 1999; Martins et al. 2001; Martins et al. 2004 a).

\section{CONCLUSÕES}

Sementes recém colhidas das cultivares Roxo e Cabelode-Negro de capim-gordura apresentam elevado índice de dormência, independentemente do local de produção.

$\mathrm{O}$ índice de esterilidade de espiguetas, a viabilidade e a dormência de sementes de capim gordura variam de acordo com o local de produção.

\section{AGRADECIMENTOS}

Ao IBAMA/Parque Nacional de Brasília, à Estação Biológica do IBGE (IBGE) e à Reserva Ecológica de Águas Emendadas pelas respectivas autorizações para as coletas das sementes do capim-gordura. À Professora Concepta Mcmanus Pimentel pelo auxílio nas análises estatísticas.

\section{REFERÊNCIAS}

ALLRED, K.W. Describing the grass inflorescence. Journal of Range Management, v.35, n.5, p.672-675. 1982.

ARONOVICH, S.; ROCHA, G.L. Gramíneas e leguminosas forrageiras de importância no Brasil Central Pecuário. Informe Agropecuário, v.11, n.132, p.3-13, 1985.

BOGDAN, A.V. Tropical pasture and folder plants. New York: Longman, 1977. 475p. (Tropical Agricultute Series).

BRASIL. Instituto Nacional de Meteorologia. Disponível em: < http://www.inmet.gov.br/html/clima $>$. Acesso em: 21 jul. 2009

BRASIL. Ministério da Agricultura e Reforma Agrária. Secretaria Nacional de Defesa Agropecuária. Departamento Nacional de Defesa Vegetal. Coordenação de Laboratório Vegetal. Regras para análise de sementes. Brasília, DF, 1992. 365 p.

BRASIL. Ministério da Agricultura, Pecuária e do Abastecimento. Instrução Normativa n. ${ }^{\circ} 30$, de 21 maio de 2008. Diário Oficial da União, Poder Executivo, Brasília, DF, 23 maio 2008, Seção 1, p. 45.

BRASIL. Ministério da Agricultura. O capim-gordura. Publicação 6. Seção de Agrostologia e Alimentação dos Animais. Rio de Janeiro, 1953. 25p. 
CARMONA, R.; MARTINS, C.R; FÁVERO, A.P. Características de sementes de gramíneas nativas do cerrado. Pesquisa Agropecuária Brasileira, v.34, n.6, p. 1067-1074, 1999.

CARMONA, R.; MARTINS, C.R; FÁVERO, A.P. Fatores que afetam a germinação de sementes de gramíneas nativas do cerrado. Revista Brasileira de Sementes, v.20, n.1, p.1622, 1998.

CURADO, T.F.C.; COSTA, N.M.S. Gramíneas para pastagens cultivadas em Minas Gerais. Informe Agropecuário, v.6, n.7, 1980.

FILGUEIRAS, T.S. Africanas no Brasil: gramíneas introduzidas da África. Cadernos de Geociências, IBGE, v.5, p.57-63, 1990.

FREITAS, G.K.; PIVELLO, V.R. A ameaça das gramíneas exóticas à biodiversidade. In: PIVELLO, V.R.; VARANDA, E.M. (Ed.). O cerrado Pé-de-Gigante: ecologia e conservação - Parque Estadual de Vassununga. Secretaria do Meio Ambiente: 2005. p.240-270.

MARTINS, C.R. Caracterização e manejo da gramínea Melinis minutiflora P. Beauv. (capim-gordura): uma espécie invasora do cerrado. 2006. 320 f. Tese (Doutorado em Ciências Biológicas) - Universidade de Brasília, Brasília.

MARTINS, C.R.; HAY, J.D.V.; CARMONA, R.; LEITE, R.R.; SCALÉA, M.; VIVALDI, L. J.; PROENÇA, C.E.B. Monitoramento e controle da gramínea invasora Melinis minutiflora (capim-gordura) no Parque Nacional de Brasília, Distrito Federal. In: CONGRESSO BRASILEIRO DE UNIDADES DE CONSERVAÇÃO, 4., 2004, Curitiba. Anais... Curitiba: Fundação O Boticário de Proteção à Natureza: Rede Nacional Pró Unidade de Conservação, 2004b, v. 2, p.5-96.
MARTINS, C.R.; LEITE, L.L.; HARIDASAN, M. Capimgordura (Melinis minutiflora P. Beauv.), uma gramínea exótica que compromete a recuperação de áreas degradadas em unidades de conservação. Revista Árvore, Viçosa, MG, v.5, p.739-747, 2004 a.

MARTINS, C.R.; LEITE, L.L.; HARIDASAN, M. Recuperação de uma área degradada pela mineração de cascalho com uso de gramíneas nativas. Revista Árvore, v.25, n.2, p. 157-166, 2001.

PARSONS, J.J. Spread of African pasture grasses to the America Tropics. Journal of Range Management, v.25, p.12-17, 1972.

PIVELLO, V.R. An expert system for the use of prescribed fires in the management of Brazilian savannas. 1992. $238 \mathrm{f}$. Thesis (PhD) - Imperial College of Science, Technology and Medicine, University of London, Ascot.

ROCHA, G.L.; CINTRA, B.; FREIRE, A; MONTANGUININI, M.F. Estudo da variação do teor germinativo de sementes de capim-gordura (Melinis minutiflora) armazenadas a baixas temperaturas e em ambiente normal. In: CONGRESSO INTERNACIONAL DE PASTAGENS, 9., 1966, São Paulo. Anais... São Paulo: Secretaria da Agricultura, 1966. v.1, p.531-534.

SKERMAN, P. J.; RIVEROS, F. Gramineas tropicales. Roma: FAO, 1992. 849p. (Collección FOA: Producción y protección vegetal, 23).

VELLO, N.A. Comportamento e variabilidade em populações de capim-gordura (Melinis minutiflora Beauv.). 1975. 186 f. Dissertação (Mestrado em Genética e Melhoramento de Plantas) - Escola Superior de Agricultura "Luiz de Queiroz", Universidade de São Paulo, Piracicaba. 